\title{
Kwalifikowanie napawania warstw trudnościeralnych pracujących w warunkach przemysłu cementowego
}

\author{
Qualifying of hardfacing surfacing layers operating \\ under conditions of the cement industry
}

\section{Streszczenie}

W pracy przedstawiono wyniki badań nad napoinami trudnościeralnymi przeznaczonymi do pracy w warunkach przemysłu cementowego. Głównym celem pracy była próba wykonania pełnego kwalifikowania procesu napawania półautomatycznego zgodnie z wymaganiami PN EN ISO 15614-7 przy wykorzystaniu drutu dającego twardości sięgające do $60 \mathrm{HRC}$ warstwy wierzchniej w jednym przejściu o ściegu szerokim na 10 i $20 \mathrm{~mm}$. Następnie próbki poddano badaniom nieniszczącym to jest badaniom wizualnym i penetracyjnym oraz badaniom niszczącym w postaci badań metalograficznych makroskopowych i mikroskopowych, badaniu twardości. Zastosowanie niniejszej normy nie daje możliwości akceptacji kwalifıkowania technologii napawania z wykorzystaniem materiałów dających bardzo twarde warstwy wierzchnie zawierające w swojej strukturze wydzielenia węglikowe.

Słowa kluczowe: napoiny trudnościeralne, drut proszkowy, PN EN ISO 15614-7, kwalifikowanie, napawanie

\begin{abstract}
The paper presents results of research on surface hard wearing designed to work in the cement industry. The main objective of the study was to perform a full qualification semiautomatic welding process in accordance with the requirements of PN EN ISO 15614-7 using a wire giving a hardness of up to $60 \mathrm{HRC}$ surface layer in a single pass with a bead wide for 10 and $20 \mathrm{~mm}$. The samples were then subjected to non-destructive testing is testing and visual and liquid penetrant testing destructive testing in the form of macroscopic and microscopic metallographic, hardness test. Application of this standard does not allow acceptance of qualification of welding technology using materials with a very hard outer layer containing in its structure separating carbide.
\end{abstract}

Keywords: hardfacing, cored wire, PN EN ISO 15614-7, qualification, surfacing weld

\section{Wstęp}

Analizując przyczyny zużycia w przemyśle możemy stwierdzić, że największy udział ok. 50\% wszystkich ubytków następuje w wyniku zużycia ściernego, około 15\% przypada na zużycie adhezyjne, a szacowany udział zużycia erozyjnego i frettingu wynosi po $8 \%$, korozja stanowi około $5 \%$, a pozostałe $14 \%$ możemy przypisać połączonemu oddziaływaniu kilku procesów. W wybranych przypadkach nawet przy braku jakiejkolwiek eksploatacji, części zapakowane i składowane na magazynie mogą ulec zużyciu w wyniku starzenia samorzutnego, który w zależności od czasu przechowywania i temperatury działającej na dany przedmiot prowadzi do utraty właściwości założonych podczas procesu produkcji. Wypadkową zużycia tworzy wiele czynników. Najważniejsze z nich przedstawiono na diagramie Ischikawy (rys. 1).

Proces produkcji cementu można podzielić na kilka głównych operacji technologicznych. Kolejno można wyróżnić etapy wydobycia i transportu surowca, kruszenie i wstępna

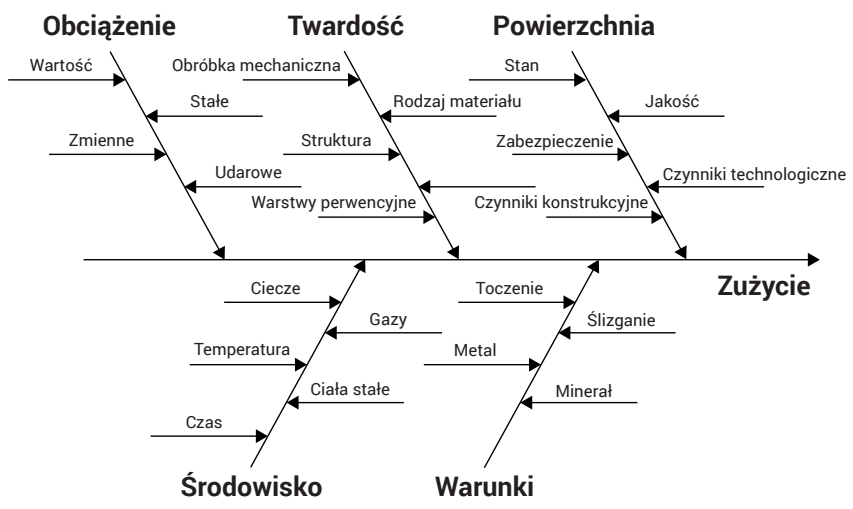

Rys. 1. Czynniki wpływające na zużycie

Fig. 1. Factors influencing on wear

homogenizacja, mielenie, wypał klinkieru oraz magazynowanie i konfekcjonowanie gotowego surowca. Każdy z tych etapów posiada specyficzne warunki pracy, a co za tym idzie różne mechanizmy zużycia. Z głównych czynników zużycia

Dr inż Robert Bęczkowski, dr inż. Marek Gucwa, - Politechnika Częstochowska.

Autor korespondencyjny/Corresponding author. rbeczkowski@spaw.pcz.pl 
możemy wyróżnić procesy zużycia ściernego, adhezyjnego, poprzez łuszczenie, zużycia wywołanego udarem oraz występującego na skutek pracy w wysokich temperaturach.

Mając z jednej strony warunki pracy i zużycia, z drugiej strony stawiamy wszelkiego rodzaju czynniki, które dają możliwość poprawy żywotności części maszyn i urządzeń. 0 sposobach i technologiach stosowanych w tym zakresie decydują uwarunkowania technologiczne, użytkowe oraz ekonomiczne poszczególnych części, podzespołów, czy też całych zespołów maszyn lub urządzeń.

Szeroką gamę procesów powodujących zużycie oraz metod używanych w naprawach bądź w prewencji możemy zaobserwować w maszynach i urządzeniach wykorzystywanych przy wszystkich etapach produkcji cementu. Pracujące urządzenia narażone są na czynniki powodujące zużycie różnego rodzaju. Jednakże do wydłużenia eksploatacji lub przywróceniu funkcjonalności poszczególnych elementów wchodzących w skład linii produkcyjnych stosuje się różnego typu technologie spawalnicze, z których najpowszechniejsze jest napawanie.

W zależności od warunków pracy stosuje się określone zasady jakimi należy się kierować przy wyborze materiału dodatkowego i metody regeneracji, czy prewencji, tak by podjęte działania były zarówno uzasadnione technologicznie jak i ekonomicznie. Jednakże z racji, iż proces spawania i procesy pokrewne są kwalifikowane jako procesy specjalne istnieje konieczność zweryfikowania zastosowanych technologii według przyjętych standardów. W przypadku napawania za taki standard można uznać PN EN ISO 15614-7. Jednakże zastosowanie tej normy w przypadku warstw trudnościeralnych niesie za sobą pewne trudności opisane w dalszej części artykułu.

$\mathrm{Na}$ etapie przygotowania surowca w przypadku wydobycia, transportu, kruszenia i homogenizacji mamy do czynienia przede wszystkim ze zużyciem ściernym, które jest wynikiem tarcia pracujących powierzchni maszyn i urządzeń o przerabiane materiały. Ma to miejsce w przypadku elementów załadowczych koparek zrywających kamień z pokładów, przesypów przenośników taśmowych, wnętrz kruszarek młotkowych, przenośników, czy przesiewaczy rolkowych, gdzie dominującym procesem jest zużycie ścierne.

Aby efektywnie poprawić trwałość elementów maszyn pracujących na działach surowcowych narażonych na ścieranie typu metal minerał stosujemy napawanie prewencyjne bądź technologiczne materiałami dającymi napoiny wysoce odporne na zużycie, zawierające węgliki pierwotne o zorientowanym w przestrzeni rozkładzie faz twardych, lub płyty o charakterystycznym ściegu napoin podnoszącym odporność na zużycie erozyjne, zawierających fazy o twardości 1500 $\div 3000$ HV w warstwach wierzchnich warstwy napawanej.

W kolejnym etapie produkcji gdzie następuje przemiał surowca na mąkę największym czynnikiem zużycia stanowi zużycie ścierne do którego dochodzi temperatura dochodząca $300{ }^{\circ} \mathrm{C}$ oraz gazy piecowe potęgujące zużycie korozyjne. Trwałość w tych warunkach powierzchni narażonych na intensywne działanie materiału zwiększamy tak jak uprzednio stosując wszelkiego rodzaju blachy kompozytowe, napawanie prewencyjne oraz regeneracyjne z wykorzystaniem materiałów dodatkowych pozwalających uzyskać struktury z twardymi wydzieleniami węglikowymi.

W następnym etapie wypału klinkieru, zawierający przygotowanie surowców do pieców obrotowych z wieżami wymienników oraz składami klinkieru. W tym etapie zużycie ścierne będzie nadal na pierwszym miejscu, lecz ze względu na występowanie wysokich temperatur, dużych przepływów gazów piecowych oraz wysokich obciążeń, występują tu także inne rodzaje zużycia jak: łuszczenie na skutek wysokich temperatur, udar oraz w wyniku korozji.
Na następnym etapie wypalony klinkier jest mielony wraz z dodatkami dając produkt końcowy. Także tutaj udział zużycia ściernego typu metal-materiał jest wciąż największy. Klinkier i jego drobne frakcje są materiałem o dużej twardości, działają więc erozyjne na elementy urządzeń, z którymi ma kontakt jak typowe ścierniwo, dlatego też przesypy, koryta transporterów, łopatki wirników wentylatorów wykonuje się z blach kompozytowych o twardościach dochodzących do 68 HRC i zdolności zachowania swych właściwości do temperatury $600^{\circ} \mathrm{C}$.

Niezależnie od możliwości jakie dają nam nowoczesne materiały poprawiające właściwości powierzchni zużycie występuje, a co za tym idzie występują koszty związane z eksploatacją, dlatego najbardziej ekonomiczne jest wyeliminowanie z pary trącej elementu urządzenia. W niektórych przypadkach jest to możliwe tak jak przy transporcie klinkieru we wszelkiego rodzaju zsypach, korytach, stołach przenośników, gdzie poprzez kratki zatrzymujące materiał na uzyskujemy warstwę buforową, a parę tracą stanowi tylko materiał przenoszony.

Ostatnim etapem technologii produkcji jest konfekcjonowanie i transport, gdzie udział materiałów polepszających właściwości powierzchni narażonych na różne formy zużycia jest najmniejszy.

$\mathrm{Na}$ podstawie podziałów podanych w powyższym dziale można stwierdzić, że nowoczesne materiały dodatkowe do napawania na stałe wpisują się w taką gałąź przemysłu cementowego, zwłaszcza przy produkcji wyrażanej w milionach ton. [1 $\div 8]$

\section{Metodyka badań}

Do prób napawania przeprowadzonych według wymagań PN EN ISO 15614-7 wykorzystano materiał podstawowy w gatunku S235JR o grubości $10 \mathrm{~mm}$, który napawano w pozycji PA metodą półautomatyczną w osłonie mieszanki M24 drutem rdzeniowym o średnicy 1,6 mm dającym możliwość uzyskania w warstwie wierzchniej wydzieleń węglikowych w osnowie niklowo borowo krzemowej pozwalających uzyskać twardości rzędu 500 $600 \mathrm{HV}$. Przebieg procesu przedstawiono na rysunku 2. Do procesu napawania zastosowano parametry źródła prądu stałego w zakresie natężenia $130 \div 150 \mathrm{~A}$, napięcia $26 \div 27 \mathrm{~V}$ z wykorzystaniem biegunowości dodatniej. [2]

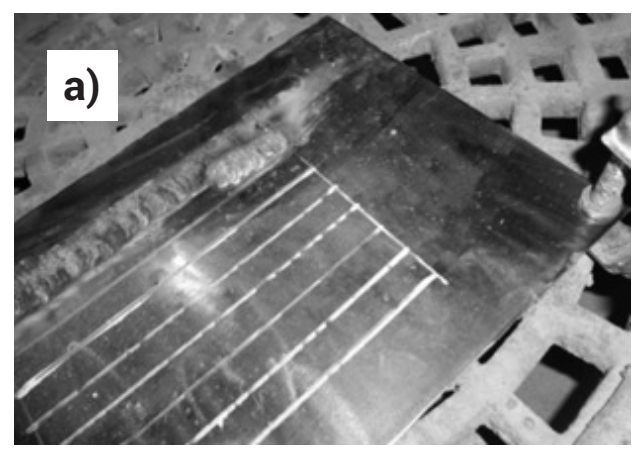

Rys. 2. Etapy procesu napawania: a) przygotowanie, b) po napawaniu [2]

Fig. 2. Surface welding process steps: a) preparation, b) after surface welding [2] 
Do celów porównawczych wykonano dwie próbki, które wykonano z zmienną szerokością ściegu odpowiednio 10 i $20 \mathrm{~mm}$. Obie próbki zostały pokryte napoiną o wymiarach 200×160 mm i średniej grubości 5 mm. Następnie wykonane próbki poddano wymaganym badaniom nieniszczącym to jest wizualnym i penetracyjnym oraz wykonano badania niszczące w zakresie badań: makroskopowych, mikroskopowych oraz twardości.
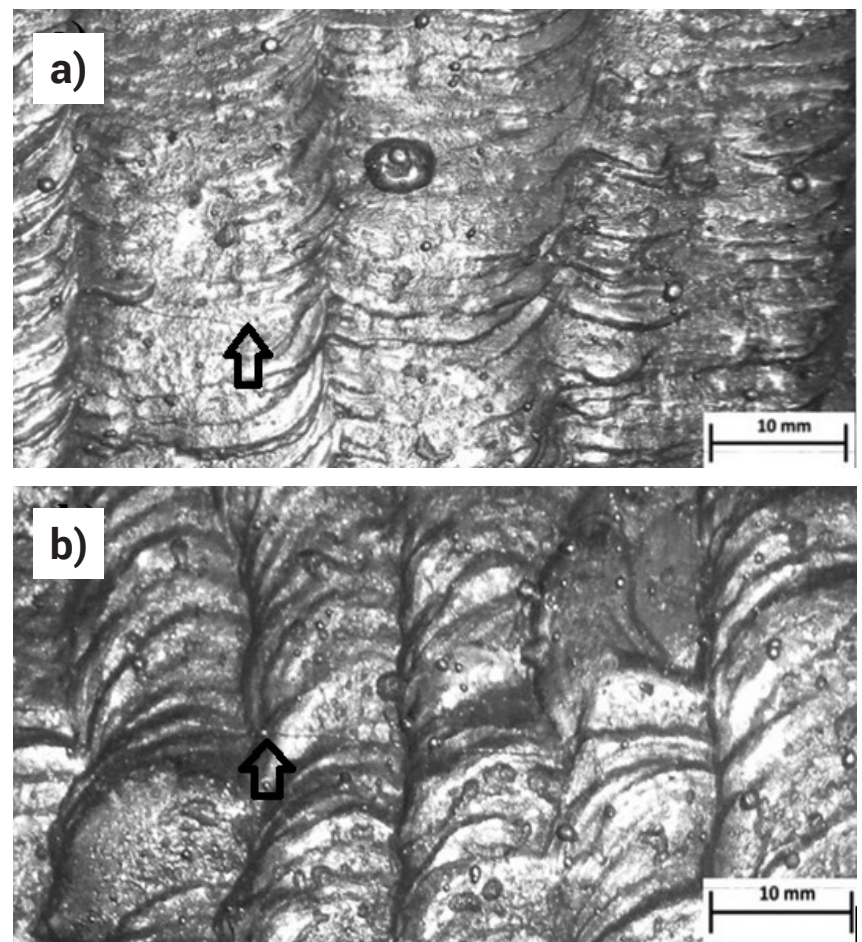

Rys. 3. Napoiny po badaniach VT (widoczne pęknięcia): a) szerokość ściegu $20 \mathrm{~mm}$, b) szerokość ściegu $10 \mathrm{~mm}$ [2]

Fig. 3. Surfacing weld after visual testing (visible cracks): a) bead width $20 \mathrm{~mm}$, b) bead width $10 \mathrm{~mm}$ [2]
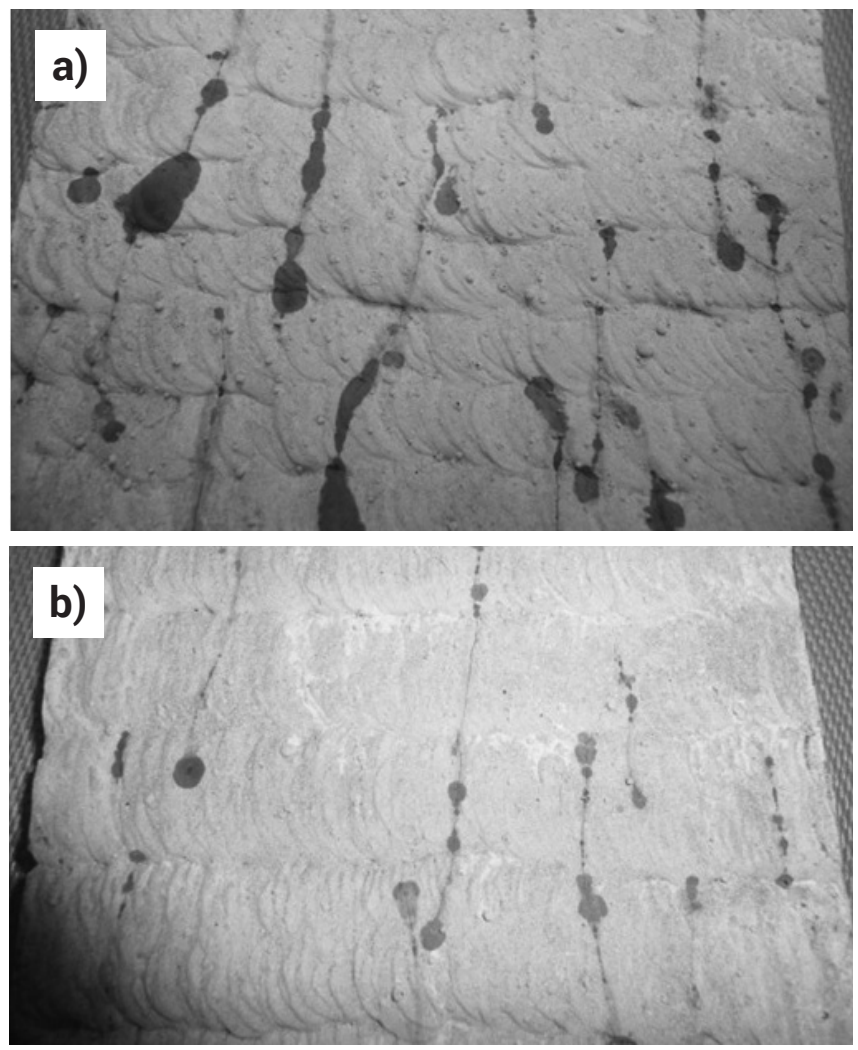

Rys. 4. Wskazania poprzecznych pęknięć napoin, a) szerokość ściegu $10 \mathrm{~mm}$, b) szerokość ściegu $20 \mathrm{~mm}$ [2]

Fig. 4. Indications of transverse cracks in surfacing welds: a) bead width $10 \mathrm{~mm}$, b) bead width $20 \mathrm{~mm}$ [2]

\section{Analiza wyników}

W przypadku badań wizualnych określono niezgodności występujące na powierzchni napoiny przedstawionych na rysunku 3 , gdzie wyraźne pęknięcia zaznaczono strzałkami.

W wyniku badań penetracyjnych potwierdzono niezgodności zaobserwowane podczas badań wizualnych i określono ich nasilenie (rys. 4). Na rysunku 4a widać, iż próbka wykonana ściegiem o szerokości $10 \mathrm{~mm}$ wykazuje się większą skłonnością do powstawania pęknięć.

Przeprowadzone badania metalograficzne makroskopowe pokazują równomierne wtopienie (rys. 5), a badania mikroskopowe dają obraz struktur uzyskanych w próbach napawania nad linią wtopienia (rys. 6) oraz pod linią wtopienia w materiale rodzimym (rys. 7 ).

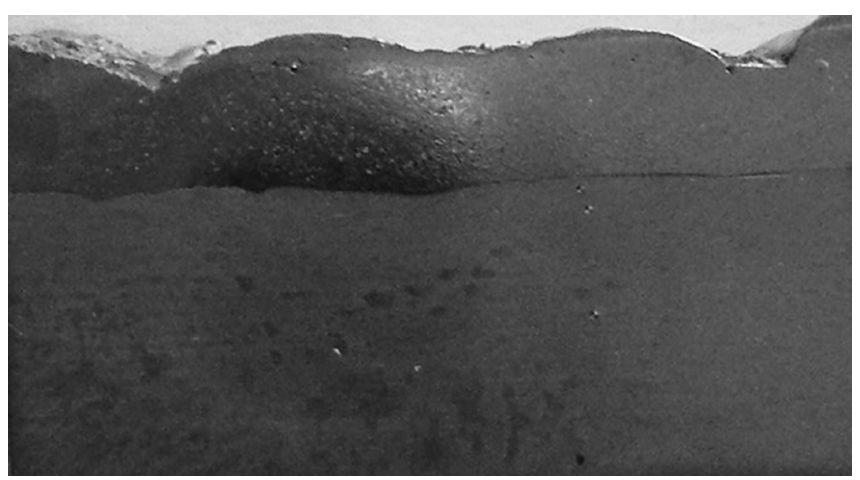

Rys. 5. Widok próbki makroskopowej

Fig. 5. View macroscopic sample
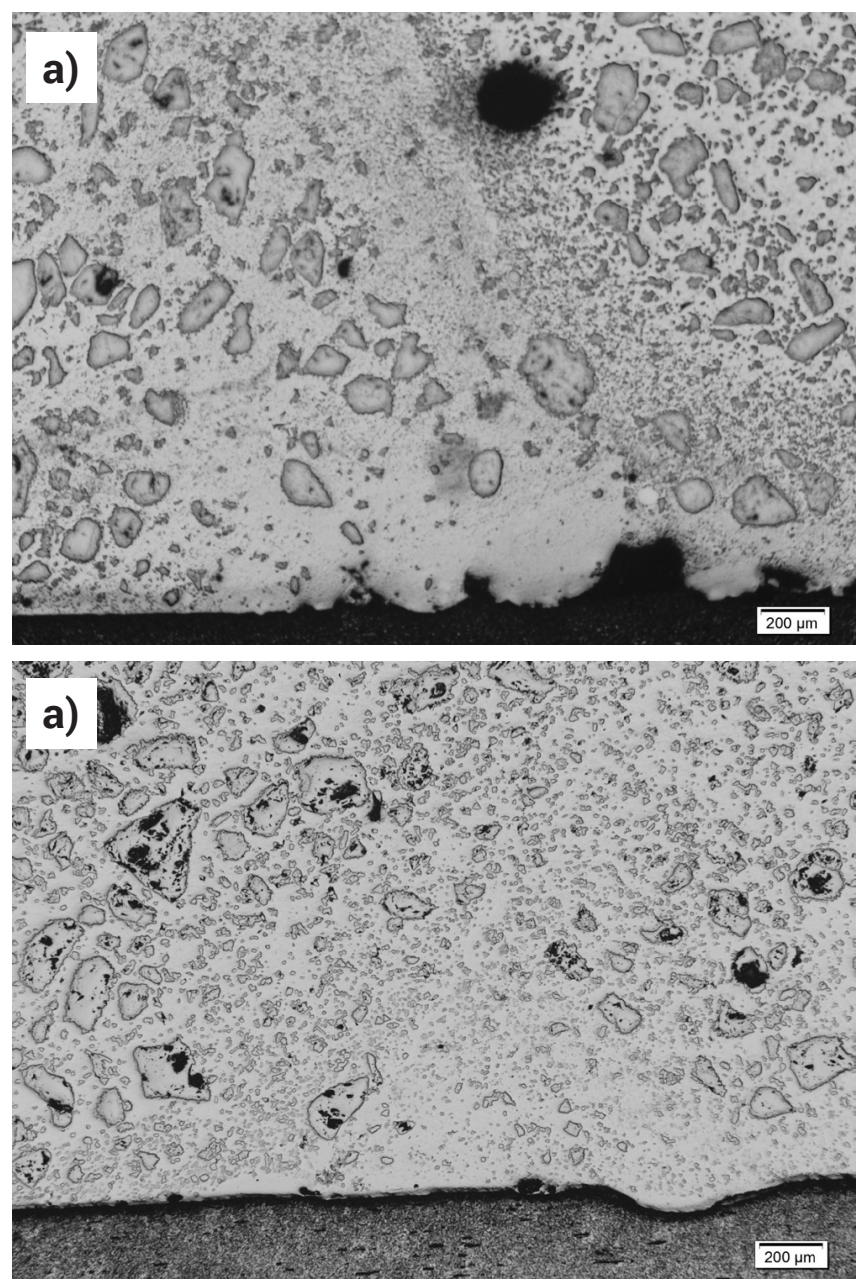

Rys. 6. Struktury napoin nad linią wtopienia: a) szerokość ściegu 20 $\mathrm{mm}, \mathrm{b})$ szerokość ściegu $10 \mathrm{~mm}$

Fig. 6. The structures surfacing welds above line of fusion: a) bead width $20 \mathrm{~mm}$, b) bead width $10 \mathrm{~mm}$ 

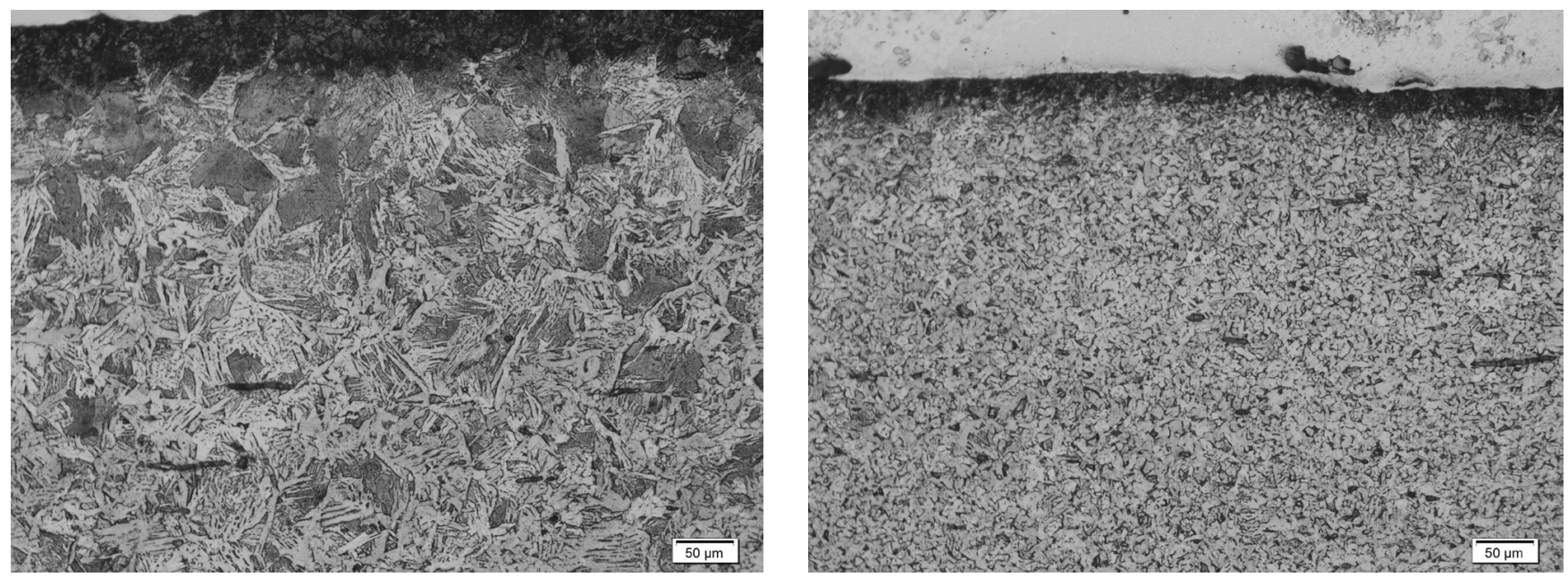

Rys. 7. Struktury materiału rodzimego pod linią wtopienia: a) szerokość ściegu $20 \mathrm{~mm}$, b) szerokość ściegu $10 \mathrm{~mm}$

Fig. 7. The structures parent material under line of fusion: a) bead width $20 \mathrm{~mm}$, b) bead width $10 \mathrm{~mm}$

Badanie twardości pozwala stwierdzić, iż uzyskujemy twardości deklarowane przez producenta już w pierwszej warstwie napoiny w zakresie $510 \div 560 \mathrm{HV} 10$. Zaobserwowano pojedyncze wskazania sięgające nawet powyżej 1000HV10 występujące na próbce o szerokości ściegu $20 \mathrm{~mm}$. Analiza twardości w materiale rodzimym daje akceptowalne wyniki na poziomie $130 \div 140 \mathrm{HV} 10$. W strefie wpływu ciepła odczyty

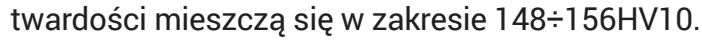

\section{Wnioski}

Zastosowanie PN EN ISO 15614-7 do kwalifikowania technologii napawania nie pozwala na dopuszczenie napoin do eksploatacji ze względu na niezgodności zaobserwowane i zidentyfikowane w badaniach wizualnych oraz potwierdzone w badaniach penetracyjnych. Badania makroskopowe dają wynik pozytywny. W przypadku analizy twardości materiału podstawowego nie daje negatywnych wyników. Na próbkach z badań mikroskopowych (rys. 7) można zauważyć różnicę w wielkości ziarna spowodowanego większym przegrzaniem materiału przy wykorzystaniu ściegu o szerokości $20 \mathrm{~mm}$. Uzyskane twardości napoin są zgodne z deklaracjami producenta drutu. Jednakże dla ściegu o szerokości $20 \mathrm{~mm}$ obserwuje się średnio większe o 10\% twardości niż dla napoin uzyskanych przy zastosowaniu wąskich ściegów (10 mm). Dla płyty napawanej szerokim ściegiem 20 mm uzyskano większe wydzielenia twardych faz w napoinie.

\section{Literatura}

[1] PN EN ISO 15614-7 Specyfikacja i kwalifikowanie technologii spawania metali-Badanie technologii spawania-Część 7 : Napawanie.

[2] T. Paczyński; Wybrane aspekty napawania nowoczesnymi materiałami dodatkowymi, Politechnika Częstochowska, Częstochowa 2015.

[3] M. Gucwa, R. Bęczkowski, Odporność na erozyjne zużycie strumieniowe napoin wykonanych drutem proszkowym samo osłonowym przy kącie padania ścierniwa $60^{\circ}$, Przegląd Spawalnictwa, 10/2011.

[4] R. Bęczkowski, Właściwości wykładzin trudnościeralnych stosowanych na elementy przesypowe wykonane techniką napawania drutem rdzeniowym", Politechnika Częstochowska, Częstochowa 2007.
[5] S. Wawak, Zarządzanie jakością-Teoria i Praktyka. Helion, Gliwice 2006.

[6] Leszek A. Dobrzański, Podstawy nauki o materiałach i metaloznawstwo, WNT, Gliwice -Warszawa 2002.

[7] M. Hebda, A. Wachal, Trybologia, WNT, Warszawa 1980.

[8] S. Peukert, Cementy powszechnego użytku i specjalne -podstawy produkcji, właściwości i zastosowanie, Stowarzyszenie Producentów Cementu, Kraków 2000. 